\author{
Military Technical College \\ Kobry Elkobbah, Cairo, \\ Egypt.
}

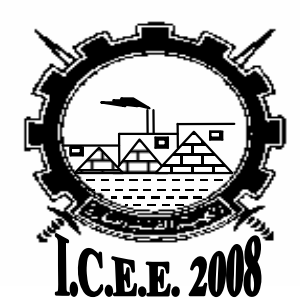

$4^{\text {th }}$ International Conference On

Chemical \& Environmental

Engineering

27-29 May 2008

Work Shop №. 01

ENVIRONMENTAL PROTECTION CHALLENGES

(EN)

\title{
NUCLEAR SAFETY PILLARS IN NUCLEAR POWER PLANTS; CONCEPTS AND TECHNOLOGY
}

\begin{abstract}
ISMAIL BADAWY*
\section{ABSTRACT}

The fast decrease of fossil fuels as energy resources is pushing the world towards more and more use of nuclear energy. The implementation of nuclear projects specially-for nuclear electricity generation should have to be done under strict regulatory conditions.

Controlled self-sustaining fission chain reactions in a nuclear reactor can provide a useful nuclear source of power. Nuclear power reactors are used for the generation of electric energy, the production of steam and hot water for town heating or industrial processes, sea-water desalination, power propulsion for marine vessels and satellites ...etc.

The nuclear materials [NMs] are the working fuel in the nuclear fission reactors. The processes undergone by NMs in their use as fuel in nuclear reactors constitute the elements of the nuclear fuel cycle [NFC]. The "front end" and the "back end" of the NFC include many processes involving different categories of NMs-mainly-mining, leaching, milling, conversion to uranium hexafluoride, enrichment in U-235 isotope and production of uranium oxides. Also, it includes the storage of irradiated fuel [IF] and spent fuel [SF], the reprocessing of SF, the production of uranium oxides and plutonium oxides from reprocessed SF and; the process of radioactive waste treatment. As a matter of fact ALL types of radioisotopes and ALL kinds of NMs that are involved in the NFC are "RADIOACTIVE" materials which would emit Beta, Gamma or $X$ radiations and/or; protons, neutrons, alpha particles and fission fragments. Such radiations ( or emissions ) could present potential hazards to the workers, to the population at large and to the environment.

Nowadays, it is well established that for the sustainability and development of the nuclear field, certain basic nuclear safety parameters (or pillars) are needed. The most important of nuclear safety pillars for the nuclear power plants are Engineering Safety, Radiation Protection, Nuclear Safeguards, Physical Protection pf Nuclear Materials and Nuclear Installations, Environmental Radiation Protection and Radiation Monitoring.

The Present study investigates the main parameters which may have effects on the safety of nuclear power plants used in peaceful applications of atomic energy.
\end{abstract}

\footnotetext{
* National Center For Nuclear Safety And Radiation Control]
} 